in vivo $35: 707-712(2021)$

doi:10.21873/invivo.12311

Review

\title{
Clinical Impact of a Perioperative Exercise Program for Sarcopenia and Overweight/Obesity Gastric Cancer
}

\author{
TORU AOYAMA ${ }^{1,2^{*}}$, MASATO NAKAZONO ${ }^{1,2^{*}}$, SHINSUKE NAGASAWA $^{1,2}$ and KENKI SEGAMI KA $^{1,2}$ \\ ${ }^{1}$ Department of Surgery, Yokohama City University, Yokohama, Japan; \\ ${ }^{2}$ Department of Gastrointestinal Surgery, Kanagawa Cancer Center, Yokohama, Japan
}

\begin{abstract}
Gastrectomy with D2 lymph node dissection and perioperative adjuvant treatment is the standard treatment for locally advanced gastric cancer. However, the morality rate is reported to be 20\%-40\% after gastrectomy for gastric cancer. Perioperative sarcopenia and obesity are strongly related to postoperative surgical complications after gastrectomy. Furthermore, recent studies have shown that postoperative surgical complications are related to long-term oncological outcomes. If we can prevent or improve perioperative sarcopenia or obesity in gastric cancer patients, the rate of postoperative surgical complications in these patients might be reduced, thereby improving the longterm oncological outcomes. Given this hypothesis, recent studies have focused on enacting perioperative exercise programs for gastric cancer patients with sarcopenia and overweight/obesity. Such exercise programs have proven promising and demonstrated some clinical benefits for gastric cancer patients with sarcopenia and overweight/obesity. However, whether or not perioperative exercise programs have clinical benefits with regard to long-term oncological outcomes in gastric cancer patients is unclear. To optimize these perioperative exercise programs for gastric cancer patients, it is necessary to clarify the benefits with regard to the long-term oncological outcomes in these patients and establish an optimal perioperative exercise program.
\end{abstract}

This article is freely accessible online.

*Both Authors contributed equally to this study.

Correspondence to: Toru Aoyama, Department of Surgery, Yokohama City University, 3-9 Fukuura, Kanazawa-ku, Yokohama 236-0004, Japan. Tel: +81 457872800,

e-mail: t-aoyama@lilac.plala.or.jp

Key Words: Exercise program, gastric cancer, sarcopenia, obesity, overweight, review.
Gastric cancer is the third-most common cancer and the second-most common cause of death in the world (1). Gastrectomy with D2 lymph node dissection and perioperative adjuvant treatment is the standard treatment for locally advanced gastric cancer (2-4). However, the morality rate is reported to be $20 \%-40 \%$ after gastrectomy for gastric cancer (5-7). Recent studies have reported that postoperative surgical complications affect the long-term oncological outcomes of gastric cancer (8-10).

Various patient-related factors, such as the age, gender, and performance status, have been reported to influence the development of postoperative surgical complications after gastrectomy for gastric cancer (11-13). Among them, perioperative sarcopenia and obesity are known to be strongly related to the occurrence of postoperative surgical complications after gastrectomy (14-16). If we can prevent or improve perioperative sarcopenia or obesity in gastric cancer patients, the rate of postoperative surgical complications in these patients might be reduced, thereby improving the long-term oncological outcomes. Given this hypothesis, recent studies have focused on introducing perioperative exercise programs for gastric cancer patients with sarcopenia and overweight/obesity.

This review summarizes the background, current status, and future perspectives of perioperative exercise programs for gastric cancer patients.

\section{Clinical Impact of Perioperative Sarcopenia on Gastric Cancer Outcomes}

Sarcopenia is a condition characterized by the loss of the skeletal muscle mass and function. Recent studies have shown that perioperative sarcopenia affects short-term outcomes in gastric cancer patients (17-19). Ma et al. evaluated the clinical influence of sarcopenia on postoperative surgical complications in 545 gastric cancer patients who received curative resection (17), where sarcopenia was defined as a low muscle mass plus a low 
muscle strength or low physical performance based on the European Working Group on Sarcopenia in Older People criteria. Among these 545 patents, 40 (7.3\%) were diagnosed with sarcopenia. The authors reported that the incidence of postoperative complications was significantly higher in patients with sarcopenia than in those without sarcopenia (21.1\% vs. 7.3\%). In addition, sarcopenia was an independent risk factor for postoperative surgical complications [hazard ratio $(\mathrm{HR})=2.330$, $95 \%$ confidence interval $(\mathrm{CI})=1.132-4.796, p=0.022]$. Similar results have been observed in other reports $(18,19)$.

In addition to its influence on short-term outcomes, however, preoperative sarcopenia was also reported to affect the long-term oncological outcomes in gastric cancer (2022). Kawamura et al. evaluated whether or not preoperative sarcopenia affected the long-term outcomes of 951 gastric cancer patients $\geq 65$ years old who received curative gastrectomy (20), with sarcopenia defined as a decreased arm muscle area of $<38.05 \mathrm{~cm}^{2}$ in men and $<27.87 \mathrm{~cm}^{2}$ in women. Among their 951 patients, 111 (11.7\%) were diagnosed with sarcopenia. Both the overall survival (OS) and cancer-specific survival (CSS) were significantly lower in patients with sarcopenia compared to those without sarcopenia. In addition, sarcopenia was an independent prognostic factor for both the OS and CSS [HR (95\% CI) for the OS: $1.82(1.32-2.47), p<0.001$; HR $(95 \% \mathrm{CI})$ for the CCS: $1.73(1.02-2.80), p=0.043]$. Similar results have also been reported in other studies $(21,22)$.

Given these previous findings, preoperative sarcopenia appears to affect both the short- and long-term oncological outcomes in gastric cancer patients.

\section{Clinical Impact of a Perioperative Exercise Program in Sarcopenic Gastric Cancer Patients}

Yamamoto et al. evaluated the effects of a preoperative exercise program and nutritional support program in 22 sarcopenia gastric cancer patients who were $\geq 65$ years old (23). The preoperative exercise program involved handgrip training, walking, and resistance training. The resistance training was performed in two patterns: one is squats, push-ups, and twisting sits-up; another is straight sits-ups, standing on tiptoes, and one arm and the opposite side leg lifted up. These were performed at home until admission for surgery. In that study, the median period of exercise program was 16 days. The authors found that the handgrip strength was $20.0 \mathrm{~kg}$ before exercise and 21.2 $\mathrm{kg}$ after exercise $(p=0.022)$. In addition, four patients became non-sarcopenic after the exercise program. However, the working speed and skeletal muscle mass index were similar before and after exercise. They concluded that nutritional support programs and preoperative exercise might reduce sarcopenia in elderly sarcopenia gastric cancer patients.

Cho et al. evaluated the safety and feasibility of a postoperative recovery exercise program developed specifically for gastric cancer patients (PREP-GC) in 24 patients who underwent laparoscopic or robot-assisted gastrectomy for gastric cancer (24). The exercise program had three phases: inhospital exercise (one week), home exercise (one week), and fitness improvement exercise (eight weeks). In the hospital phase, exercise was selected to increase the range of motion after gastrectomy. All exercises were under the supervision of an exercise specialist. Walking was also encouraged whenever possible. In the home exercise phase, the exercise program was designed to improve the range of motion after discharge from the hospital. A handout illustrating the home exercise regimen was provided to the patients. They were recommended to perform the bed and home exercise regimens at least twice a day and to report their daily activity. In the fitness exercise phase, the program was designed to improve the function and reduction in muscle volume after surgery. Patients performed exercise three times a week. The eight weeks of resistance exercise were divided into four periods. Among the 24 patients enrolled in this study, 20 completed the PREP-GC. There were no adverse events related to the exercise program. The adherence rate was $79.4 \%$ and the compliance rate was $99.4 \%$ in this study. After completing the PREP-GC, patients showed improvement in muscular strength, cardiopulmonary function, emotional functioning, and global health status. The authors concluded that a systematic exercise intervention program might have some clinical benefit for patients undergoing gastrectomy for gastric cancer.

Given the above findings, perioperative exercise programs might be safe and feasible, and have some clinical influence on the outcomes of patients undergoing gastrectomy for gastric cancer. However, the clinical benefits of such exercise intervention for patients after gastrectomy during the perioperative period should be clarified in a randomized trial.

\section{Clinical Impact of a Perioperative Overweight or Obese Status on Gastric Cancer Outcomes}

Overweight and obesity are defined as an abnormal or excessive fat accumulation that presents a risk to one's health. A body mass index (BMI) over 25 is considered overweight, while that over 30 is considered obese (25). Recent studies have shown that perioperative overweight and obesity affect both the short- and long-term outcomes of gastric cancer patients $(26,27)$.

Kambara et al. evaluated the clinical impact of the preoperative BMI in 460 patients with locally advanced gastric cancer who received curative resection (26). The patients were classified into groups with BMI $<18.5 \mathrm{~kg} / \mathrm{m}^{2}$, $18.5-25 \mathrm{~kg} / \mathrm{m}^{2}$, and $\geq 25 \mathrm{~kg} / \mathrm{m}^{2}$. Upon comparing the patients' characteristics, those with a BMI $\geq 25 \mathrm{~kg} / \mathrm{m}^{2}$ had a longer operation (239vs. 206 and 229, $p=0.0610$ ), more blood loss (420 vs. 222 and 300, $p=0.0200)$, and more frequent intra-abdominal abscess (16\% vs. $3 \%$ and $4 \%$, 
$p=0.0012)$ than those with a BMI of $<18.5$ and $18.5-25$ $\mathrm{kg} / \mathrm{m}^{2}$. The 5-year relapse-free survival rate was $47.6 \%$ in the BMI $<18.5 \mathrm{~kg} / \mathrm{m}^{2}$ group, $54.3 \%$ in the BMI $18.5-25$ $\mathrm{kg} / \mathrm{m}^{2}$ group, and $40.0 \%$ in the BMI $>25 \mathrm{~kg} / \mathrm{m}^{2}$ group, respectively $(p=0.0614)$, while the 5 -year overall survival rate was $50.1 \%$ in the BMI $<18.5 \mathrm{~kg} / \mathrm{m}^{2}$ group, $62.5 \%$ in the BMI $18.5-25 \mathrm{~kg} / \mathrm{m}^{2}$ group, and $53.8 \%$ in the BMI $>25 \mathrm{~kg} / \mathrm{m}^{2}$ group $(p=0.0413)$. The authors found that the BMI was a significant risk factor for both short- and long-term oncological outcomes in locally advanced gastric cancer patients. They concluded that a greater surgical stress, fewer dissected lymph nodes, and a higher rate of postoperative infective complications might contribute to the unfavorable prognosis of patients with a $\mathrm{BMI} \geq 25 \mathrm{~kg} / \mathrm{m}^{2}$.

We et al. evaluated the clinical influence of overweight $\left(\mathrm{BMI} \geq 25 \mathrm{~kg} / \mathrm{m}^{2}\right)$ in gastric cancer patients who received gastrectomy using a meta-analysis (27). This meta-analysis included 23 studies with 20,678 gastric cancer patients (4897 with BMI $\geq 25 \mathrm{~kg} / \mathrm{m}^{2}$ and 15781 with BMI $<25 \mathrm{~kg} / \mathrm{m}^{2}$ ). Overweight patients had significantly longer operation times $(p<0.00001)$ and more blood loss $(p=0.001)$ than those with a BMI $<25 \mathrm{~kg} / \mathrm{m}^{2}$. The incidence of anastomosis leakage $(p=0.002)$ and pancreatic fistula was significantly higher in patients with a BMI $>25 \mathrm{~kg} / \mathrm{m}^{2}$ than in those with a BMI $<25 \mathrm{~kg} / \mathrm{m}^{2}$ ( $p=0.002$ and $p<0.00001$, respectively). In addition, patients with a BMI $\geq 25 \mathrm{~kg} / \mathrm{m}^{2}$ showed a significantly poorer survival than those with a BMI $<25$ $\mathrm{kg} / \mathrm{m}^{2}$ (relative risk: $1.14 ; 95 \% \mathrm{CI}=1.07-1.20, p<0.0001$ ). However, the mortality rate and length of hospital stay were similar between the two groups.

Notably, the "obesity paradox" has been proposed for various malignancies (28-30). In gastric cancer, Tokunaga et al. evaluated the relationships between the BMI and long-term oncological outcomes in 7,925 gastric cancer patients who underwent gastrectomy (31). The patients were divided into those with a BMI $<25 \mathrm{~kg} / \mathrm{m}^{2}(\mathrm{n}=6799, \mathrm{~N}-\mathrm{BMI})$ and those with a BMI $\geq 25 \mathrm{~kg} / \mathrm{m}^{2}$ (n=1126, H-BMI). They found that the 5year overall survival was significantly better in the H-BMI group than in the N-BMI group $(81.5 \%$ vs. $74.1 \%$, respectively; $p<0.001)$. Similar results have also been observed in other studies $(32,33)$. Given these previous findings, although overweight and obesity do have negative effects on the short-term oncological outcomes, the clinical impact of overweight and obesity on the long-term oncological outcomes in gastric cancer must be further evaluated.

\section{Clinical Impact of a Perioperative Exercise Program on Obese Gastric Cancer Patients}

Overweight and obesity are risk factors for the perioperative management and postoperative surgical complications after gastrectomy for gastric cancer. Some studies have evaluated the efficacy of perioperative exercise programs in reducing postoperative surgical complications in gastric cancer patients with overweight or obesity. Cho et al. evaluated whether or not a preoperative exercise program would be safe and effective for obese gastric cancer patients (34). The training program included stretching exercise, aerobic exercise, and resistance training. The aerobic exercise involved using swimming, bicycle ergometer, dancing, or jogging. These exercises were performed at least three days per week. In this study, $30 \mathrm{kcal} / \mathrm{kg} /$ week was expected to be the energy expenditure of the exercise. Resistance training was carried out at least one time per week. The exercise program continued for four weeks. In this study, 18 patients were enrolled in the exercise group, and 54 patients enrolled in the control group were matched to the exercise group patients. After the exercise program, body weight, abdominal circumference, and the BMI were significantly lower after the exercise than before the exercise, following the fourweek program. When comparing the surgical results between the exercise group and control group, the median blood loss was slightly lower in the exercise group than in the control group (105 ml vs. $130 \mathrm{ml}, p=0.692)$. In addition, the incidence of abdominal postoperative surgical abscess $(0 \%$ vs. $18.5 \%, p=0.089)$ and anastomotic leakage ( $0 \%$ vs. $16.7 \%$, $p=0.125$ ) tended to be lower in the exercise group than in the control group. The authors concluded that preoperative exercise was safe and had clinical benefit in reducing postoperative surgical complications.

\section{Future Perspective and Ongoing Trial}

Since 2010, several ongoing studies have been examining perioperative exercise program for gastric cancer patients. A Taiwanese group is conducting a randomized control trial comparing the efficacy of a rehabilitation exercise program with the usual care, in 160 gastric cancer patients who received gastrectomy (ClinicalTrials.gov Identifier: NCT04593134). Their exercise group performed a 12-week regimen of home-based walking exercise comprising walking at a moderate intensity for $40 \mathrm{~min}, 3$ times a week. The primary endpoint is the quality of life using EORTC QLQC30 and STO-22, and the secondary endpoints are fatigue, emotional distress, sleep quality, and circadian rhythms.

A UK group is conducting a randomized control trial comparing the efficacy of multimodal pre-operative rehabilitation program with the usual care during neo-adjuvant therapy in 50 esophago-gastric cancer patients (ClinicalTrials.gov Identifier: NCT02950324). The patients in the rehabilitation group performed 15 weeks of exercise and received nutritional support and psychological rehabilitation in the form of 'Medical Coaching'. The primary endpoint is the cardiopulmonary exercise performance, and the secondary endpoints are changes in insulin resistance, quality of life, and grip-strength. 
A Chinese group is conducting a randomized control trial comparing efficacy of a pre-operative rehabilitation program with the usual care during neo-adjuvant therapy in 82 gastric cancer patients with metabolic syndrome (ClinicalTrials.gov Identifier: NCT02649348). The patients in the rehabilitation group climbed 6 flights of stairs (approximately 20 meters in height) at least 6 times as a daily routine and performed adaptive simulated training of restrictive ventilation dysfunction following abdominal surgery using a full elastic breathable abdominal bandage. The primary endpoint is the incidence of postoperative surgical complications.

Bausys et al. evaluated whether or not home-based rehabilitation can reduce postoperative morbidity in patients who received gastrectomy for gastric cancer (ClinicalTrials.gov Identifier: NCT04223401). They conducted a multi-center, open-label randomized control trial comparing the incidence of 90-day postoperative morbidity after gastrectomy for gastric cancer between patients with and without rehabilitation. In their trial, 128 patients were enrolled into either the intervention or control group. The secondary outcomes of the study were the physical and nutritional status, anxiety and depression level, quality of life, postoperative mortality rates, and full completion of the oncological treatment.

Although perioperative exercise programs have been shown to have clinical influence on the outcomes of various malignancies, several points need to be clarified to optimize the perioperative exercise program for gastric cancer patients. First, the definition and evaluation methods of sarcopenia were unclear in the reviewed studies. Second, the optimal duration and methods of perioperative exercise were unclear. Third, the clinical benefits of the perioperative exercise on the long-term oncological outcomes were unclear. If these points could be clarified, an effective program might be able to be established for gastric cancer patients.

\section{Conclusion}

Preoperative sarcopenia and overweight/obesity might have some clinical influence on both the short- and long-term oncological outcomes in gastric cancer patients. Perioperative exercise programs proved promising and had some clinical benefits for gastric cancer patients with sarcopenia as well as overweight/obesity. However, whether or not these programs had clinical benefits on the long-term oncological outcomes in gastric cancer remains unclear. To optimize the perioperative exercise program for gastric cancer patients, it is necessary to clarify the benefits of these programs on the long-term oncological outcomes in gastric cancer patients and establish optimal perioperative exercise programs.

\section{Conflicts of Interest}

The Authors have no conflicts of interest to declare regarding this study.

\section{Authors' Contributions}

Both Authors contributed equally in all aspects of this study.

\section{References}

1 Bray F, Ferlay J, Soerjomataram I, Siegel RL, Torre LA and Jemal A: Global cancer statistics 2018: GLOBOCAN estimates of incidence and mortality worldwide for 36 cancers in 185 countries. CA Cancer J Clin 68: 394-424, 2018. PMID: 30207593. DOI: $10.3322 /$ caac. 21492

2 Japanese Gastric Cancer Association: Japanese gastric cancer treatment guidelines 2018 (5th edition). Gastric Cancer 24(1): 121, 2021. PMID: 32060757. DOI: 10.1007/s10120-020-01042-y

3 NCCN. NCCN Clinical Practice Guidelines in Oncology. 2018. Available at: http://www.nccn.org [Last accessed on November 1, 2020]

4 Smyth EC, Verheij M, Allum W, Cunningham D, Cervantes A and Arnold D; ESMO Guidelines Committee: Gastric cancer: ESMO Clinical Practice Guidelines for diagnosis, treatment and follow-up. Ann Oncol 27: v38-v49, 2016. PMID: 27664260. DOI: $10.1093 /$ annonc/mdw350

5 Sasako M, Sano T, Yamamoto S, Kurokawa Y, Nashimoto A, Kurita A, Hiratsuka M, Tsujinaka T, Kinoshita T, Arai K, Yamamura Y and Okajima K; Japan Clinical Oncology Group: D2 lymphadenectomy alone or with para-aortic nodal dissection for gastric cancer. N Engl J Med 359: 453-462, 2008. PMID: 18669424. DOI: 10.1056/NEJMoa0707035

6 Park SH, Lim DH, Sohn TS, Lee J, Zang DY, Kim ST, Kang JH, Oh SY, Hwang IG, Ji JH, Shin DB, Yu JI, Kim KM, An JY, Choi MG, Lee JH, Kim S, Hong JY, Park JO, Park YS, Lim HY, Bae JM and Kang WK; ARTIST 2 investigators: A randomized phase III trial comparing adjuvant single-agent $\mathrm{S} 1$, S-1 with oxaliplatin, and postoperative chemoradiation with S1 and oxaliplatin in patients with node-positive gastric cancer after D2 resection: the ARTIST 2 trial. Ann Oncol S09237534(20)43172-2, 2020. PMID: 33278599. DOI: 10.1016/ j.annonc.2020.11.017

7 de Steur WO, van Amelsfoort RM, Hartgrink HH, Putter H, Meershoek-Klein Kranenbarg E, van Grieken NCT, van Sandick JW, Claassen YHM, Braak JPBM, Jansen EPM, Sikorska K, van Tinteren H, Walraven I, Lind P, Nordsmark M, van Berge Henegouwen MI, van Laarhoven HWM, Cats A, Verheij M, van de Velde $\mathrm{CJH}$ and CRITICS Investigators: Adjuvant chemotherapy is superior to chemoradiation after D2 surgery for gastric cancer in the per-protocol analysis of the randomized CRITICS trial. Ann Oncol S0923-7534(20)43156-4, 2020. PMID: 33227408. DOI: 10.1016/j.annonc.2020.11.004

8 Hayashi T, Yoshikawa T, Aoyama T, Hasegawa S, Yamada T, Tsuchida K, Fujikawa H, Sato T, Ogata T, Cho H, Oshima T, Rino Y, and Masuda M: Impact of infectious complications on gastric cancer recurrence. Gastric Cancer 18: 368-374, 2015. PMID: 24634097. DOI: 10.1007/s10120-014-0361-3

9 Maezawa Y, Aoyama T, Ju M, Komori K, Kano K, Sawazaki S, Numata M, Hayashi T, Yamada T, Tamagawa H, Sato T, Ogata T, Cho H, Oshima T, Yukawa N, Yoshikawa T, Masuda M and Rino Y: The impact of severe infectious complications on longterm prognosis for gastric cancer. Anticancer Res 40: 4067-4074, 2020. PMID: 32620654. DOI: 10.21873/anticanres.14404 
10 Aurello P, Cinquepalmi M, Petrucciani N, Moschetta G, Antolino L, Felli F, Giulitti D, Nigri G, D’Angelo F, Valabrega $\mathrm{S}$ and Ramacciato G: Impact of anastomotic leakage on overall and disease-free survival after surgery for gastric carcinoma: a systematic review. Anticancer Res 40: 619-624, 2020. PMID: 32014902. DOI: 10.21873/anticanres.1399

11 Kanda M: Preoperative predictors of postoperative complications after gastric cancer resection. Surg Today 50: 3-11, 2020. DOI: 10.1007/s00595-019-01877-8

12 An JY, Kim KM, Kim YM, Cheong JH, Hyung WJ, and Noh SH: Surgical complications in gastric cancer patients preoperatively treated with chemotherapy: their risk factors and clinical relevance. Ann Surg Oncol 19: 2452-2458, 2012. PMID: 22395984. DOI: $10.1245 / \mathrm{s} 10434-012-2267-9$

13 Guner A, Kim SY, Yu JE, Min IK, Roh YH, Roh C, Seo WJ, Cho M, Choi S, Choi YY, Son T, Cheong JH, Hyung WJ, Noh $\mathrm{SH}$ and Kim HI: Parameters for predicting surgical outcomes for gastric cancer patients: simple is better than complex. Ann Surg Oncol 25: 3239-3247, 2018. PMID: 30069658. DOI: 10.1245/s 10434-018-6684-2

14 Tsujinaka T, Sasako M, Yamamoto S, Sano T, Kurokawa Y, Nashimoto A, Kurita A, Katai H, Shimizu T, Furukawa H, Inoue S, Hiratsuka M, Kinoshita T, Arai K and Yamamura Y: Gastric Cancer Surgery Study Group of Japan Clinical Oncology Group. Influence of overweight on surgical complications for gastric cancer: results from a randomized control trial comparing D2 and extended para-aortic D3 lymphadenectomy (JCOG9501). Ann Surg Oncol 14: 355-361, 2007. PMID: 17146738. DOI: 10.1245/s 10434-006-9209-3

15 Okada K, Nishigori T, Obama K, Tsunoda S, Hida K, Hisamori $\mathrm{S}$ and Sakai Y: The incidence of postoperative complications after gastrectomy increases in proportion to the amount of preoperative visceral fat. J Oncol 2019: 8404383, 2019. PMID: 31929799. DOI: $10.1155 / 2019 / 8404383$

16 Tamura T, Sakurai K, Nambara M, Miki Y, Toyokawa T, Kubo N, Tanaka H, Muguruma K, Yashiro M and Ohira M: Adverse effects of preoperative sarcopenia on postoperative complications of patients with gastric cancer. Anticancer Res 39: 987-992, 2019. PMID: 30711985. DOI: 10.21873/anticanres.13203

17 Ma BW, Chen XY, Fan SD, Zhang FM, Huang DD, Li B, Shen $\mathrm{X}$, Zhuang $\mathrm{CL}$ and $\mathrm{Yu} \mathrm{Z}$ : Impact of sarcopenia on clinical outcomes after radical gastrectomy for patients without nutritional risk. Nutrition 61: 61-66, 2019. PMID: 30703570. DOI: $10.1016 /$ j.nut.2018.10.025

18 Chen FF, Zhang FY, Zhou XY, Shen X, Yu Z and Zhuang CL: Role of frailty and nutritional status in predicting complications following total gastrectomy with D2 lymphadenectomy in patients with gastric cancer: a prospective study. Langenbecks Arch Surg 401: 813-822, 2016. PMID: 27485549. DOI: 10.1007/s00423-016-1490-4

19 Wang SL, Zhuang CL, Huang DD, Pang WY, Lou N, Chen FF, Zhou CJ, Shen X and Yu Z: Sarcopenia adversely impacts postoperative clinical outcomes following gastrectomy in patients with gastric cancer: A prospective study. Ann Surg Oncol 23: 556564, 2016. PMID: 26668085. DOI: 10.1245/s10434-015-4887-3

20 Kawamura T, Makuuchi R, Tokunaga M, Tanizawa Y, Bando E, Yasui $\mathrm{H}$, Aoyama $\mathrm{T}$, Inano $\mathrm{T}$ and Terashima M: Long-term outcomes of gastric cancer patients with preoperative sarcopenia. Ann Surg Oncol 25: 1625-1632, 2018. PMID: 29633095. DOI: $10.1245 / \mathrm{s} 10434-018-6452-3$
21 Waki Y, Irino T, Makuuchi R, Notsu A, Kamiya S, Tanizawa Y, Bando E, Kawamura T and Terashima M: Impact of preoperative skeletal muscle quality measurement on long-term survival after curative gastrectomy for locally advanced gastric cancer. World J Surg 43: 3083-3093, 2019. PMID: 31482345. DOI: 10.1007/s00268-019-05145-1

$22 \mathrm{Hu}$ CL, Jin XH, Yuan ZD, Xiong SW, Zhang L, Hou JN, Ao S, Wu JL, Shi HP, Ji JF and Lyv GQ: Prognostic significance of preoperative skeletal muscle status in patients with gastric cancer after radical gastrectomy. Asia Pac J Clin Nutr 28: 442-449, 2019. PMID: 31464390. DOI: 10.6133/apjcn.201909_28(3).0003

23 Yamamoto K, Nagatsuma Y, Fukuda Y, Hirao M, Nishikawa K, Miyamoto A, Ikeda M, Nakamori S, Sekimoto M, Fujitani K and Tsujinaka T: Effectiveness of a preoperative exercise and nutritional support program for elderly sarcopenic patients with gastric cancer. Gastric Cancer 20: 913-918, 2017. PMID: 28032232. DOI: 10.1007/s10120-016-0683-4

24 Cho I, Son Y, Song S, Bae YJ, Kim YN, Kim HI, Lee DT and Hyung WJ: Feasibility and effects of a postoperative recovery exercise program developed specifically for gastric cancer patients (PREP-GC) undergoing minimally invasive gastrectomy. J Gastric Cancer 18: 118-133, 2018. PMID: 29984062. DOI: 10.5230/jgc.2018.18.e12

25 WHO Expert Consultation: Appropriate body-mass index for Asian populations and its implications for policy and intervention strategies. Lancet 363: 157-163, 2004. DOI: 10.1016/S0140-6736(03)15268-3

26 Kambara Y, Yuasa N, Takeuchi E, Miyake H, Nagai H, Yoshioka $\mathrm{Y}$, Okuno $\mathrm{M}$ and Miyata $\mathrm{K}$ : Overweight or obesity is an unfavorable long-term prognostic factor for patients who underwent gastrectomy for stage II/III gastric cancer. World J Surg 43: 1766-1776, 2019. PMID: 30820737. DOI: 10.1007/s00268019-04969-1

27 Wu XS, Wu WG, Li ML, Yang JH, Ding QC, Zhang L, Mu JS, $\mathrm{Gu}$ J, Dong P, Lu JH and Liu YB: Impact of being overweight on the surgical outcomes of patients with gastric cancer: a metaanalysis. World J Gastroenterol 19: 4596-4606, 2013. PMID: 23901238. DOI: 10.3748/wjg.v19.i27.4596

28 Darbas T, Forestier G, Leobon S, Pestre J, Jesus P, Lachatre D, Tubiana-Mathieu N, Descazeaud A and Deluche E: Impact of body composition in overweight and obese patients with localised renal cell carcinoma. In Vivo 34: 2873-2881, 2020. PMID: 32871827. DOI: 10.21873/invivo.12115

$29 \mathrm{Hu}$ C, Zhang Q, Jin X, Zhang L, Zhang Y, Zhu Q, Tang M, Lyv $\mathrm{G}$ and Shi H: A paradox between preoperative overweight/ obesity and change in weight during postoperative chemotherapy and its relationship to survival in stage II and III colorectal cancer patients. Clin Nutr S0261-5614(20)30582-3, 2020 PMID: 33183882. DOI: 10.1016/j.clnu.2020.10.039

30 Martinez-Tapia C, Diot T, Oubaya N, Paillaud E, Poisson J, Gisselbrecht M, Morisset L, Caillet P, Baudin A, Pamoukdjian F, Broussier A, Bastuji-Garin S, Laurent M and Canouï-Poitrine F: The obesity paradox for mid- and long-term mortality in older cancer patients: a prospective multicenter cohort study. Am J Clin Nutr nqaa238, 2020. PMID: 32889525. DOI: 10.1093/ajcn/nqaa238

31 Tokunaga M, Hiki N, Fukunaga T, Ohyama S, Yamaguchi T and Nakajima T: Better 5-year survival rate following curative gastrectomy in overweight patients. Ann Surg Oncol 16: 32453251, 2009. PMID: 19636624. DOI: 10.1245/s10434-009$0645-8$ 
32 Struecker B, Biebl M, Dadras M, Chopra S, Denecke C, Spenke J, Heilmann AC, Bahra M, Sauer IM, Pratschke J and Andreou A: The impact of obesity on outcomes following resection for gastric cancer. Dig Surg 34: 133-141, 2017. PMID: 27694744. DOI: $10.1159 / 000449043$

33 Kocoglu H, Dogan H, Oguz B, Ocak Serin S, Okuturlar Y, Gunaldi M, Erismis B, Ozdemir B, Tural D, Hursitoglu M, Harmankaya $\mathrm{O}$ and Kumbasar A: Comparison of survival rates, tumor stages, and localization in between obese and nonobese patients with gastric cancer. Gastroenterol Res Pract 2016: 9382750, 2016. PMID: 27418926. DOI: 10.1155/2016/ 9382750
34 Cho H, Yoshikawa T, Oba MS, Hirabayashi N, Shirai J, Aoyama T, Hayashi T, Yamada T, Oba K, Morita S, Sakamoto J and Tsuburaya A: Matched pair analysis to examine the effects of a planned preoperative exercise program in early gastric cancer patients with metabolic syndrome to reduce operative risk: The Adjuvant Exercise for General Elective Surgery (AEGES) study group. Ann Surg Oncol 21: 2044-2050, 2014. PMID: 24671637. DOI: $10.1245 / \mathrm{s} 10434-013-3394-7$

Received December 28, 2020

Revised January 18, 2021

Accepted January 21, 2021 